\title{
Association between delirium in the intensive care unit and subsequent neuropsychiatric disorders
}

Kyla N. Brown ${ }^{1}$, Andrea Soo ${ }^{2,3}$, Peter Faris ${ }^{1,2,4}$, Scott B. Patten ${ }^{1,2,5,6}$, Kirsten M. Fiest ${ }^{1,2,3,4,5,6+}$ and Henry T. Stelfox ${ }^{1,2,3,4^{*}+}$ (D)

\begin{abstract}
Background: Patients in the intensive care unit (ICU) are known to be at increased risk of developing delirium, but the risk of subsequent neuropsychiatric disorders is unclear. We therefore sought to examine the association between the presence of delirium in the ICU and incident neuropsychiatric disorders (including depressive, anxiety, trauma-and-stressor-related, and neurocognitive disorders) post-ICU stay among adult medical-surgical ICU patients.

Methods: Retrospective cohort study utilizing clinical and administrative data from both inpatient and outpatient healthcare visits to identify the ICU cohort and diagnostic information 5 years prior to and 1 year post-ICU stay. Patients $\geq 18$ years of age admitted to one of 14 medical-surgical ICUs across Alberta, Canada, January 1, 2014-June 30, 2016, and survived to hospital discharge were included. The main outcome of interest was a new diagnosis of any neuropsychiatric disorder 1 year post-ICU stay. The exposure variable was delirium during the ICU stay identified through any positive delirium screen by the Intensive Care Unit Delirium Screening Checklist (ICDSC) during the ICU stay.

Results: Of 16,005 unique patients with at least one ICU admission, 4033 patients were included in the study of which 1792 (44\%) experienced delirium during their ICU stay. The overall cumulative incidence of any neuropsychiatric disorder during the subsequent year was 19.7\% for ICU patients. After adjusting for hospital characteristics using log-binomial regression, patients with delirium during the ICU stay had a risk ratio (RR) of 1.14 (95\% confidence interval [Cl] 0.98-1.33) of developing any neuropsychiatric disorder within 1 year post-ICU compared to those who did not experience delirium. Delirium was significantly associated with neurocognitive disorders (RR 1.59, 95\% Cl 1.08-2.35), but not depressive disorders (RR 1.16, 95\% Cl 0.92-1.45), anxiety (RR 1.16, 95\% $\mathrm{Cl} 0.92-1.47$ ), and trauma-and-stressor-related (RR $0.82,95 \% \mathrm{Cl} 0.53-1.28$ ) disorders.
\end{abstract}

Conclusions: The diagnosis of new onset of neurocognitive disorders is associated with ICU-acquired delirium. In this study, significant associations were not observed for depressive, anxiety, and trauma-and-stressor-related disorders.

Keywords: Cohort studies, Mental health, Cognition disorders, Critical care, Adult

\footnotetext{
* Correspondence: tstelfox@ucalgary.ca

${ }^{+}$Kirsten M. Fiest and Henry T. Stelfox are co-senior authors.

${ }^{1}$ Department of Community Health Sciences, University of Calgary, Calgary,

Alberta, Canada

${ }^{2}$ Alberta Health Services, Calgary, Alberta, Canada

Full list of author information is available at the end of the article
}

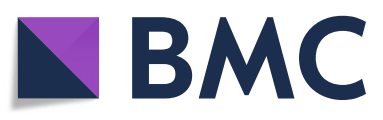

(c) The Author(s). 2020 Open Access This article is licensed under a Creative Commons Attribution 4.0 International License, which permits use, sharing, adaptation, distribution and reproduction in any medium or format, as long as you give appropriate credit to the original author(s) and the source, provide a link to the Creative Commons licence, and indicate if changes were made. The images or other third party material in this article are included in the article's Creative Commons licence, unless indicated otherwise in a credit line to the material. If material is not included in the article's Creative Commons licence and your intended use is not permitted by statutory regulation or exceeds the permitted use, you will need to obtain permission directly from the copyright holder. To view a copy of this licence, visit http://creativecommons.org/licenses/by/4.0/. The Creative Commons Public Domain Dedication waiver (http://creativecommons.org/publicdomain/zero/1.0/) applies to the data made available in this article, unless otherwise stated in a credit line to the data. 


\section{Background}

Delirium is an acute state characterized by an onset of confusion and decline in cognitive ability often occurring in hospitalized patients [1-5]. The prevalence of delirium in the intensive care unit (ICU) ranges from 20 to $80 \%$ [1]. Delirium is associated with an increased length of ICU and hospital stay [6] and mortality [7, 8]. A number of studies have suggested that delirium-induced stress response may predispose patients to the development of neuropsychiatric disorders $[3-5,9,10]$, in particular dementia [11]. The hypothesized mechanisms for this relationship include biological and chemical changes in the brain as a response to stress and inflammation [12], disturbances in circadian rhythm [12, 13], and the use of sedatives, memory deficits, and treatment-related trauma $[14,15]$.

Risk factors for delirium have similarly been implicated in the psychiatric morbidity of critically ill patients post-stay $[14,15]$. A number of studies suggest that patients admitted to the ICU are at an increased risk of subsequently developing neuropsychiatric disorders [1618]. Neuropsychiatric disorders can include depressive, anxiety, trauma-and-stressor-related, and neurocognitive disorders [16-18]. However, there are few and limited population-based research studies using physiciandiagnosed codes to examine the association between delirium in the ICU and subsequent neuropsychiatric disorders post-stay. Given the high prevalence of delirium, it is important to understand whether these ICU patients are at increased risk of neuropsychiatric disorders relative to patients who did not experience delirium [19-21].

The aim of the current study was to evaluate the association between delirium in the ICU and a new diagnosis of any neuropsychiatric disorder in adult medicalsurgical ICU patients during 1 year post-ICU stay. We hypothesized that patients with delirium in the ICU would be at an increased risk of developing neuropsychiatric disorders during the 1-year follow-up period.

\section{Methods}

This retrospective cohort study was conducted and reported in accordance with recommendations of the Strengthening the Reporting of Observational Studies in Epidemiology (STROBE) statement [22]. The Conjoint Health Research Ethics Board at the University of Calgary approved this study (REB17-0389).

\section{Study cohort}

We identified all adult ICU patients ( $\geq 18$ years) who were admitted to one of the 14 medical-surgical ICU across Alberta, Canada (population 4.2 million people), between January 1, 2014, and June 30, 2016 [23]. Data was collected 5 years prior to an individual ICU admission and up to 1 year after hospital discharge to identify individuals who had a healthcare visit for a diagnosis of a neuropsychiatric disorder. Patients were excluded if their ICU stay was less than $24 \mathrm{~h}$, if they died in ICU, if they did not have any delirium assessment in ICU, if they did not survive to hospital discharge, if their ICU admission did not link with hospital admission data within a 2-h window, or if their home was located outside of Alberta (to allow for complete follow-up). In the case of multiple ICU admissions during the study period, the patient's first eligible ICU admission was used as the primary admission. Patients with an inpatient or outpatient healthcare visit for which any neuropsychiatric disorder (i.e., depressive, anxiety, trauma-and-stressor, and neurocognitive disorders) was listed as a post-admit comorbidity or a secondary diagnosis in the 5 years prior to and during their primary ICU admission were excluded (i.e., diagnostic codes suggestive of a preexisting neuropsychiatric disorder). Hospital discharge dates ranged from January 9, 2014, to March 13, 2017. Patients were followed up until 1 year posthospital discharge, death, or study end (October 31, 2017), whichever occurred first.

\section{Data sources}

We used clinical and administrative databases from Alberta Health Services and Alberta Health (Discharge Abstracts Database [DAD], National Ambulatory Care Reporting System [NACRS], Physician Claims, Vital Statistics, and eCritical Tracer Database), previously successfully used in research studies [24, 25]. eCritical Tracer is a bedside electronic medical record that prospectively captures demographic, clinical, and patient outcomes for all patients admitted to an Alberta ICU [26]. The DAD captures patients who received hospitalbased care and has up to 25 Canadian Enhancement of International Statistical Classification of Diseases, 10th Revision, fields for diagnostic codes. The NACRS captures data for all hospital-based and community-based emergency or ambulatory care and has up to 10 Canadian Enhancement of International Statistical Classification of Diseases, 10th Revision, fields for diagnostic codes. Physician Claims captures patients who received care from an outpatient clinic (primary or specialty) and has up to 3 Canadian Enhancement of International Statistical Classification of Diseases, 9th Revision, fields for diagnostic codes. Vital Statistics data is provided to Alberta Health Services from Alberta Health. All deaths occurring in Alberta must be registered with Alberta Vital Statistics. The DAD, NACRS, and Physician Claims were available until October 31, 2017, and Vital Statistics were available until December 31, 2017, at the time of data extraction. 


\section{Delirium}

The primary exposure was ever having delirium at any point during the ICU stay. Delirium was measured using the validated Intensive Care Delirium Screening Checklist (ICDSC) [27], which is documented as part of standard of care by the bedside nurse once every nursing shift (i.e., twice a day) [28]. The checklist is scored out of eight categories that include the level of consciousness, inattention, disorientation, hallucinations/delusions/ psychosis, psychomotor agitation, inappropriate speech or mood, sleep wake/cycle disturbance, and symptom fluctuation [29]. Each category is coded as present (i.e., a score of 1) if the patient meets the criteria listed, for a maximum score of 8 . Patients who scored $\geq 4$ on the ICDSC at any time during the ICU stay were categorized as ever having delirium and those with all of their ICDS $\mathrm{C}$ scores $<4$ on all ratings were categorized as never having delirium. The ICDSC has a sensitivity of $99 \%$ and a specificity of $64 \%$ in a medical-surgical ICU patient population [29]. Sensitivity analyses were conducted to determine whether there was a dose-response according to the duration of delirium in the ICU (one calendar day of delirium vs. two or more calendar days of delirium). One calendar day of delirium was determined by having at least one ICDSC score of $\geq 4$ on that calendar day.

\section{Neuropsychiatric disorders}

Neuropsychiatric disorders identified in previous systematic reviews to potentially be associated with delirium were included as outcome measures [30-33], including depressive (such as major depressive disorders), anxiety (such as generalized anxiety disorders), trauma-andstressor-related (such as acute stress disorders or posttraumatic stress disorder), and neurocognitive (such as dementia, respective symptoms for neurocognitive disorders include difficulty performing tasks in high stimuli environment, forgetting words, and experiencing personality changes [34]) disorders. Neuropsychiatric disorders were identified through physician-diagnosed ICD 9/10 codes that were captured in the DAD, NACRS, and Physician Claims databases (see Additional file 1). Validated coding algorithms were used to identify depressive [35] and anxiety [36] disorders. A neuropsychiatrist and psychiatrist developed coding algorithms for trauma-and-stressor-related and neurocognitive disorders as there are currently no published validated coding algorithms for these disorders. The two clinicians independently reviewed all DSM- 5 codes as well as previous studies reporting these disorders identifying those ICD 9/10 codes for trauma-and-stressor-related and neurocognitive disorders. Disagreements were resolved through discussion. The primary outcome was a healthcare visit (e.g., hospital stay, emergency or ambulatory, and outpatient clinic) that was a post-admit comorbidity or a secondary diagnosis of a neuropsychiatric disorder (i.e., depressive, anxiety, trauma-and-stressor-related, and neurocognitive disorders). Neuropsychiatric disorders were examined together to identify individuals who were diagnosed with any of the four neuropsychiatric disorders and then for each disorder separately.

\section{Covariates}

Characteristics potentially associated with delirium during the ICU stay and neuropsychiatric disorders at a 1year follow-up were identified a priori [37, 38]. Characteristics included age, sex, ICU admission reason (medical, surgical, neurological, trauma), Acute Physiology and Chronic Health Evaluation (APACHE) II score, Charlson Comorbidity Index (CCI), Glasgow Coma Scale (GCS), transfer delay $\geq 24 \mathrm{~h}$, invasive mechanical ventilation (yes/no), non-invasive mechanical ventilation (yes/ no), continuous renal replacement therapy (yes/no), vasoactive medications (yes/no), ICU size (categorized as $<20$ beds vs. $\geq 20$ beds), teaching hospital (yes/no), ICU length of stay (categorized as $<7$ days vs. $\geq 7$ days), and last Sequential Organ Failure Assessment (SOFA) score.

\section{Statistical analysis}

Descriptive statistics for demographic characteristics and covariates were examined using median (interquartile range $[\mathrm{IQR}]$ ) for continuous variables and frequencies (with percentages) for categorical variables. Group comparisons were made using the Mann-Whitney $U$ test for continuous non-normally distributed variables and chisquared tests for binary variables. The cumulative incidence of any and each neuropsychiatric disorder was calculated by identifying the number of new cases of the neuropsychiatric disorder within 1 year (the numerator) divided by the total number of patients at risk of developing the disorder (the denominator). The incidence density of any and each neuropsychiatric disorder was calculated by identifying the number of new cases of the neuropsychiatric disorder within 1 year (the numerator) divided by the total number of person years for patients at risk of developing the disorder (the denominator). For patients who did not survive to 1 year post-ICU stay, time from hospital discharge to death was taken as time at risk.

Associations between delirium in the ICU and new neuropsychiatric disorders were assessed using logbinominal regression analyses (in which exponentiated regression coefficients represent risk ratios). Supplementary analyses were also conducted for each disorder separately (depressive, anxiety, trauma-and-stressor-related, and neurocognitive disorders) using log-binomial regression analyses. We adjusted all models for all covariates previously identified. Analyses were conducted in STATA version 14 (StataCorp LP; College Station, TX, USA) and R, version 3.5.1 (The R Project for Statistical Computing, http://www.r-project.org/). 


\section{Results}

\section{Study population}

From January 1, 2014, to June 30, 2016, there were 16, 005 unique patients from the 14 study ICUs with at least one ICU stay. Of these ICU admissions, there were 11, 166 unique ICU patients potentially eligible for inclusion in the study (exclusion reasons included ICU stay $<24 \mathrm{~h}$, death in ICU, no delirium assessment, died in hospital following first ICU admission, patient's ICU admission did not link with the DAD admission data within a 2-h window, non-Albertan patients). Of those, 6442 patients had a healthcare visit within the previous 5 years that included a diagnosis of a neuropsychiatric disorder, leaving 4033 patients who satisfied the inclusion criteria (Fig. 1). The baseline characteristics of patients with and without pre-existing neuropsychiatric disorders are outlined in Additional file 2. Among the 4033 patients included in the study, 475 died (12\%) within the 1-year follow-up.

Patient and hospital characteristics of the primary study cohort are summarized in Table 1. The overall prevalence of delirium during the ICU stay was $44 \%$ (95\% confidence interval $[\mathrm{CI}] 43-46 \%)(n=1792)$. The median age of ICU patients in this study was 60 years (IQR 46-71 years), 68\% $(n=2744)$ were male, the most common reason for an ICU admission was medical (e.g., pneumonia, cardiac arrest, sepsis, etc.), and the median length of ICU stay was 4.1 days (IQR 2.3-7.6 days). The median Charlson Comorbidity Index was 1 (IQR 0-3), median SOFA score upon ICU admission was 6 (IQR 39), and median APACHE II score upon ICU admission was 18 (IQR 13-24).

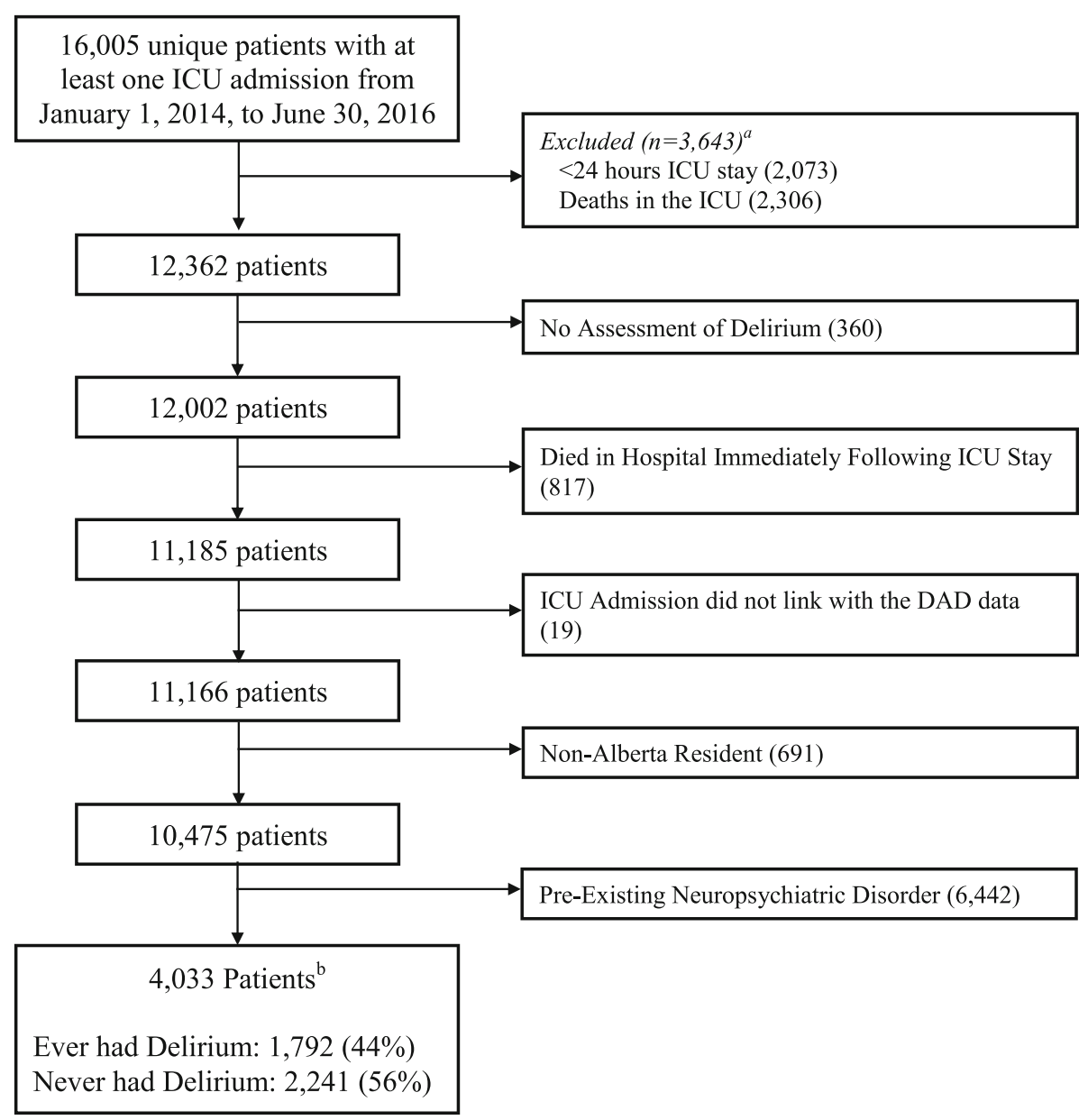

${ }^{\text {a }}$ The excluded total will not be the sum of each criteria as some patients had both exclusions.

${ }^{b_{5}}$ of the 4,033 patients did not have the full 1-year follow-up for DAD, NACRS and physician claims. And 2 of the 4,033 patients did not have the full 1-year follow-up for vital statistics.

Fig. 1 Study flow chart 
Table 1 Patient and hospital characteristics during the intensive care unit for those who survived to hospital discharge

\begin{tabular}{|c|c|c|c|c|}
\hline \multirow[b]{2}{*}{ Characteristic } & \multirow{2}{*}{$\begin{array}{l}\text { Total } \\
(\boldsymbol{n}=4033)\end{array}$} & \multicolumn{2}{|l|}{ Delirium $^{\text {a }}$} & \multirow[t]{2}{*}{$p$ value } \\
\hline & & Delirium $(\boldsymbol{n}=1799)$ & No delirium $(\boldsymbol{n}=2234)$ & \\
\hline \multicolumn{5}{|l|}{ Patient characteristics on ICU admission } \\
\hline Age, median (IQR) years & $60(46-71)$ & $60(46-70)$ & $60(46-71)$ & 0.85 \\
\hline Male sex, no. (\%) & $2744(68.0)$ & $1278(71.0)$ & $1466(65.6)$ & $<0.001$ \\
\hline \multicolumn{5}{|l|}{ Reason for ICU admission, no. $(\%)^{\mathrm{b}}$} \\
\hline Medical & $2172(54.9)$ & $939(52.8)$ & $1233(56.7)$ & $<0.001$ \\
\hline Surgical & $1221(30.9)$ & $449(25.2)$ & $772(35.5)$ & \\
\hline Neurological & $205(5.2)$ & $143(8.0)$ & $62(2.9)$ & \\
\hline Trauma & $356(9.0)$ & $249(14.0)$ & $107(4.9)$ & \\
\hline \multicolumn{5}{|l|}{ Comorbidities, no. $(\%)^{c}$} \\
\hline AIDS & $6(0.2)$ & $1(0.1)$ & $5(0.2)$ & 0.24 \\
\hline Acute myocardial infarction & $270(6.7)$ & $140(7.8)$ & $130(5.8)$ & 0.011 \\
\hline Cancer & $587(14.6)$ & $210(11.7)$ & $377(16.8)$ & $<0.001$ \\
\hline Cerebrovascular disease & $201(5.0)$ & $143(8.0)$ & $58(2.6)$ & $<0.001$ \\
\hline Congestive heart failure & $435(10.8)$ & $206(11.5)$ & $229(10.2)$ & 0.19 \\
\hline Chronic obstructive pulmonary disease & $699(17.3)$ & $321(17.9)$ & $378(16.9)$ & 0.38 \\
\hline Diabetes & $518(12.8)$ & $230(12.8)$ & $288(12.9)$ & 0.99 \\
\hline Diabetes + complications & $694(17.2)$ & $324(18.1)$ & $370(16.5)$ & 0.19 \\
\hline Hemiplegia or paraplegia & $90(2.2)$ & $53(3.0)$ & $37(1.7)$ & 0.005 \\
\hline Metastatic cancer & $167(4.1)$ & $57(3.2)$ & $110(4.9)$ & 0.006 \\
\hline Mild liver disease & $196(4.9)$ & $108(6.0)$ & $88(3.9)$ & 0.002 \\
\hline Moderate/severe liver disease & $104(2.6)$ & $62(3.5)$ & $42(1.9)$ & 0.002 \\
\hline Peptic ulcer disease & $153(3.8)$ & $72(4.0)$ & $81(3.6)$ & 0.51 \\
\hline Peripheral vascular disease & $228(5.7)$ & $106(5.9)$ & $122(5.4)$ & 0.52 \\
\hline Renal disease & $207(5.1)$ & $97(5.4)$ & $110(4.9)$ & 0.47 \\
\hline Rheumatoid disease & $61(1.5)$ & $29(1.6)$ & $32(1.4)$ & 0.62 \\
\hline Charlson Comorbidity Score, median (IQR) & $1(0-3)$ & $1(0-2)$ & $1(0-3)$ & 0.17 \\
\hline SOFA score on ICU admission, median (IQR) & $6(3-9)$ & $7(5-10)$ & $5(3-7)$ & $<0.001$ \\
\hline APACHE II score on ICU admission, median (IQR) & $18(13-23)$ & $20(15-26)$ & $16(11-21)$ & $<0.001$ \\
\hline Glasgow Coma Scale score on ICU admission, median (IQR) & $15(13-15)$ & $14(11-15)$ & $15(15-15)$ & $<0.001$ \\
\hline \multicolumn{5}{|l|}{ Interventions received in ICU } \\
\hline Invasive mechanical ventilation & $2535(62.9)$ & $1463(81.3)$ & $1072(48.0)$ & $<0.001$ \\
\hline Non-invasive mechanical ventilation & $569(14.1)$ & $276(15.3)$ & $293(13.1)$ & 0.043 \\
\hline Continuous renal replacement therapy & $181(4.5)$ & $145(8.1)$ & $36(1.6)$ & $<0.001$ \\
\hline Vasoactive medications & $1770(43.9)$ & $1035(57.5)$ & $735(32.9)$ & $<0.001$ \\
\hline \multicolumn{5}{|l|}{ Hospital characteristics } \\
\hline$\geq 20$ ICU beds, no. (\%) & $2161(53.6)$ & $1084(60.3)$ & $1077(48.2)$ & $<0.001$ \\
\hline$\geq 600$ hospital beds, no. (\%) & $2404(59.6)$ & $1186(65.9)$ & $1218(54.5)$ & $<0.001$ \\
\hline Teaching hospital, no. (\%) & $3304(81.9)$ & $1571(87.3)$ & $1733(77.6)$ & $<0.001$ \\
\hline$\geq 24 \mathrm{~h}$ in ICU after ready for ICU discharge & $1505(37.3)$ & $695(38.6)$ & $810(36.3)$ & 0.12 \\
\hline
\end{tabular}

Patient characteristics on ICU discharge

Length of ICU stay, median (IQR) days

$4.1(2.3-7.6) \quad 6.6(3.8-12.4)$

$2.9(1.9-4.8)$

$<0.001$

Abbreviations: AIDS Auto-immune deficiency syndrome, APACHE II score Acute Physiology and Chronic Health Evaluation II Score, ICU Intensive care unit, SOFA Sequential Organ Failure Assessment

aPatients who scored positive for delirium by the Intensive Care Unit Delirium Screening Checklist (ICDSC) of a score greater than or equal to 4 at any time during the ICU were categorized as ever having delirium

${ }^{\mathrm{b}}$ Mutually exclusive categories; 77 patients missing data

cNon-mutually exclusive categories 


\section{Incidence of neuropsychiatric disorders}

During the 1-year follow-up period, 794 patients (19.7\%, 95\% CI 18.5-20.9\%) had a healthcare visit for a newly diagnosed neuropsychiatric disorder. The cumulative incidences of depressive, anxiety, trauma-and-stressorrelated, and neurocognitive disorders were 10.1\% (95\% CI $9.2-11.1 \%$ ), $8.8 \%$ (95\% CI $8.0-9.7 \%$ ), $2.9 \%$ (95\% CI $2.3-3.4 \%$ ), and $3.5 \%$ (95\% CI $2.9-4.1 \%$ ), respectively. The incidence density for those who developed any neuropsychiatric disorder during the 1-year follow-up was 213 (95\% CI 200-226) per 1000 person years. The incidence densities of depressive, anxiety, trauma-andstressor-related, and neurocognitive disorders were 110 (95\% CI 100-120) per 1000 person years, 96 (95\% CI 86-105) per 1000 person years, 31 (95\% CI 25-36) per 1000 person years, and 38 (95\% CI 32-44) per 1000 person years, respectively.

\section{Delirium and neuropsychiatric disorders}

Patients who ever had delirium in the ICU had 1.14 (95\% CI 0.98-1.33) times the risk of developing a neuropsychiatric disorder within 1 year compared to those who never had delirium in the ICU (Table 2). The adjusted risk ratios of depressive, anxiety, trauma-andstressor-related, and neurocognitive disorders were 1.16 (95\% CI 0.92-1.45), 1.16 (95\% CI 0.92-1.47), 0.82 (95\% CI 0.53-1.28), and 1.59 (95\% CI 1.08-2.35), respectively, for those with delirium compared to those without delirium in the ICU (Table 2, see Additional file 3 for unadjusted estimates and Additional file 4 for adjusted estimates). A sensitivity analysis using duration of delirium, defined as (1) never having delirium, (2) one calendar day of delirium, and (3) two or more calendar days of delirium, showed similar adjusted risk ratios for any neuropsychiatric disorder, as well as each specific neuropsychiatric disorder of interest except neurocognitive disorders (see Additional file 5). Patients with two or more calendar days of delirium in the ICU had 2.14

Table 2 Association between delirium during the intensive care unit and subsequent neuropsychiatric disorders

\begin{tabular}{lll}
\hline & \multicolumn{2}{l}{ Risk ratio (95\% confidence interval) } \\
\cline { 2 - 3 } Outcome & Crude & Adjusted $^{\mathbf{b}}$ \\
\hline Any neuropsychiatric disorder & $1.36(1.20-1.54)$ & $1.14(0.98-1.33)$ \\
Depressive & $1.45(1.20-1.74)$ & $1.16(0.92-1.45)$ \\
Anxiety & $1.31(1.08-1.60)$ & $1.16(0.92-1.47)$ \\
Trauma-and-stressor related & $1.14(0.79-1.63)$ & $0.82(0.53-1.28)$ \\
Neurocognitive & $2.19(1.57-3.09)$ & $1.59(1.08-2.35)$ \\
\hline
\end{tabular}

aReference group is "never" had ICU delirium

${ }^{\mathrm{b}}$ Adjusted for age, sex, ICU admission reason (medical, surgical, neurological, trauma), APACHE II score, Charlson Comorbidity score, Glasgow Coma Scale, transfer delay, $\geq 24 \mathrm{~h}$, invasive mechanical ventilation (yes/no), continuous renal replacement therapy (yes/no), and vasoactive medications (yes/no), $\geq 20$ ICU beds, teaching hospital (yes/no), ICU length of stay (categorized as $<7$ days vs. $\geq 7$ days), and last SOFA score
(95\% CI 1.40-3.28) times the risk of developing a neurocognitive disorder within the 1 year compared to those who never had delirium, whereas patients with one calendar day of delirium did not have a significantly different risk of developing a neurocognitive disorder within the 1 year compared to those who never had delirium (see Additional file 5).

\section{Discussion}

This retrospective cohort study examined the association between delirium in the ICU and subsequent healthcare visits for a neuropsychiatric disorder, captured in both inpatient and outpatient settings. There was a high prevalence of delirium in the study cohort, which is consistent with the existing literature on the prevalence of delirium in the ICU $[1,39]$. In addition, a high cumulative incidence of neuropsychiatric disorders was observed during the 1-year follow-up. Patients who ever had delirium during the ICU were at a significantly increased risk of developing neurocognitive disorders at 1year follow-up, specifically those with delirium for two or more days.

There is a growing awareness of neuropsychiatric disorders following an ICU stay [20,40]. A study by Paparrigopoulos et al. [41] of 48 ICU survivors found that patients with pre-existing neuropsychiatric disorders are at an increased risk of developing subsequent disorders post-ICU stay. Patients without pre-existing disorders also face a high risk of developing new neuropsychiatric disorders post-ICU stay as shown from this study. This is in addition to the general population prevalence of depression reported to be $4.7 \%$ in 2012 [42], and the general population estimate of a lifetime anxiety disorder diagnosis ranges from 14.6 [43] to $24.9 \%$ [44]. A study by Granja et al. [15] of 464 ICU patients and Chahraoui et al. [45] of $20 \mathrm{ICU}$ patients examined risk factors for neuropsychiatric disorders post-ICU stay, suggesting that recollection (e.g., those who do not remember their stay) and negative memories (e.g., persistent nightmares) associated with an ICU stay often predicted a worse quality of life and risk for neuropsychiatric sequelae. Additional risk factors for ICU patients developing neuropsychiatric disorders, specifically depression, stem from factors such as age, gender, the nature of therapies provided in the ICU, length of stay, and diagnosis of sepsis $[46,47]$. The implications of a growing awareness of neuropsychiatric disorders following an ICU stay are that care plans for patients post-ICU may benefit from surveillance and targeted therapies.

Our study showed a significant association between delirium in the ICU and a subsequent diagnosis of a neurocognitive disorder. However, our study did not find significant associations for depressive, anxiety, and trauma-and-stressor-related disorders, potentially due to 
the comorbid relationship between depression and anxiety, as depressive disorders may present more prominent symptoms leading to the misclassification of anxiety disorders as depressive disorders [48]. Furthermore, individuals may present with symptoms of depression and not be formally diagnosed [34]. Given the high burden and risk of neuropsychiatric disorders following an ICU stay, further evaluations of psychiatric health and cognitive-based interventions should be a priority for ICU patients in follow-up clinics [49]. Critical care physicians should be aware of the potential long-term ramifications of an ICU stay, in addition to the physical health of ICU patients [50]. Implementation of delirium screening tools during the ICU stay may lead to earlier detection and treatment and potentially help to mitigate the negative effects of delirium and the associated risk of subsequent neurocognitive disorders [13].

Strengths of this study include the large sample size and population-based nature of the data, as well as the ability to control for a number of risk factors for delirium and neuropsychiatric disorders. Data were also available for pre-existing neuropsychiatric disorders. Moreover, this study was able to utilize a provincial, validated delirium identification tool [28]. Our study findings have some limitations. First, trauma-and-stressorrelated disorders and neurocognitive disorders did not have a validated coding scheme; therefore, the code list developed may not include all the ICD 9/10 codes related to each disorder, resulting in possible underestimates of the incidence and risk ratio. Second, our study sample may have underestimated the incidence of neuropsychiatric disorders as we only captured healthcare visits to medical professionals, potentially missing visits to other therapists. This measurement approach is likely to identify patients with more severe neuropsychiatric disorders and provide more specific (and less sensitive) estimates. A subset of patients may also choose not to seek help due to mental health-associated stigma [51] or have difficulty identifying symptoms [52]. Third, the follow-up period post-ICU stay was only 1 year in length, which may not be long enough for some neuropsychiatric disorders (e.g., dementia) to manifest and be diagnosed. Fourth, our study excluded patients with previously diagnosed neuropsychiatric disorders and is therefore likely to provide a conservative estimate of the association between delirium and new or worsening neuropsychiatric disorders. Fifth, we did not capture sedative medication or alcohol exposure, which may lead to residual confounding.

\section{Conclusions}

Our data suggest that patients who experience delirium during the ICU are at increased risk of developing a neurocognitive disorder in the 1 year following their ICU stay. This risk appears to be dose dependent. Significant associations with depressive, anxiety, and trauma-andstressor-related disorders were not observed, but the confidence intervals associated with risk ratios for these disorders do not necessarily preclude the existence of clinically significant associations between delirium and these conditions. Future clinical and research efforts should focus on early detection and management of delirium to mitigate the potential development of neurocognitive disorders post-ICU stay. Consideration should be given to monitoring ICU patients with delirium for long-term neurocognitive disorders.

\section{Supplementary information}

Supplementary information accompanies this paper at https://doi.org/10. 1186/s13054-020-03193-x.

\section{Additional file 1. Frequency of Diagnostic Codes for Each Neuropsychiatric Disorder Per Visit Per Database for All Patient Data.: The data presented in additional file 1 present frequency of diagnostic codes for each neuropsychiatric disorder per visit per database (DAD, NACRS, and Physician Claims) for all patient data.}

Additional file 2. Characteristics of Those With and Without Pre-Existing Neuropsychiatric Disorders. The data presented in additional file 2 compare characteristics of patients with and without pre-existing neuropsychiatric disorders from five years prior to ICU admission.

Additional file 3. Unadjusted Risk Ratios for Delirium, Patient Characteristics and Neuropsychiatric Disorders. The data presented in additional file 3 present detailed unadjusted risk ratios for delirium, patient characteristics and each neuropsychiatric disorder.

Additional file 4. Adjusted Models for Delirium and Neuropsychiatric Disorders. The data presented in additional file 4 present detailed models for delirium and each neuropsychiatric disorder.

Additional file 5. Sensitivity Analyses Between Delirium and No Delirium/one calendar day/two or more calendar days of Delirium in the Intensive Care Unit. The data presented in additional file 5 is the outputs of a sensitivity analysis between delirium and no delirium/one calendar day/two or more calendar days of delirium in the ICU.

\section{Abbreviations}

APACHE II: Acute Physiology and Chronic Health Evaluation II; CCl: Charlson Comorbidity Index; GCS: Glasgow Coma Scale; SOFA: Sequential Organ Failure Assessment; Cl: Confidence Interval; IQR: Inter-Quartile Range; ICDSC: Intensive Care Delirium Screening Checklist; AIDS: Aquired ImmunoDeficiency Syndrome; DAD: Discharge Abstracts Database; ICU: Intensive care unit; NACRS: National Ambulatory Care Reporting System;

STROBE: Strengthening the Reporting of Observational Studies in Epidemiology

\section{Acknowledgements}

We would like to thank Dr. Zahinoor Ismail for assisting in the development of a coding algorithm that was used to identify ICD 9/10 codes for traumaand-stressor-related and neurocognitive disorders.

\section{Authors' contributions}

KNB made substantial contributions to the conception and design of the project, analyzed and interpreted the data, and drafted the manuscript. AS aided in the analysis and interpretation of the data and contributed to revising the manuscript. PF and SBP made substantial contributions to the conception and design of the project and contributed to revising the manuscript. KMF and HTS made substantial contributions to the conception and design of the project and drafted the manuscript. The author(s) read and approved the final manuscript. 


\section{Funding}

Kyla Brown was supported by a W21C Health Services Research Scholarship Alberta Graduate Student Scholarship, and the Queen Elizabeth II Scholarship. Henry T Stelfox was supported by an Embedded Clinician Research Award from the Canadian Institutes of Health Research. Funding bodies did not play a role in the design of the study and collection, analysis, and interpretation of data, as well as the writing of the manuscript.

\section{Availability of data and materials}

The datasets generated and analyzed during the current study are not publicly available due to identifiable information of patients but are available from the corresponding author on reasonable request.

\section{Ethics approval and consent to participate}

The Conjoint Health Research Ethics Board at the University of Calgary approved this study (REB17-0389).

\section{Consent for publication}

Not applicable.

\section{Competing interests}

The authors declare that they have no competing interests.

\section{Author details}

'Department of Community Health Sciences, University of Calgary, Calgary, Alberta, Canada. ${ }^{2}$ Alberta Health Services, Calgary, Alberta, Canada. ${ }^{3}$ Department of Critical Care Medicine, University of Calgary, 3134 Hospital Drive, Calgary, Alberta T2N 2T9, Canada. ${ }^{4} \mathrm{O}$ Brien Institute for Public Health, University of Calgary, Calgary, Alberta, Canada. ${ }^{5}$ Hotchkiss Brain Institute, University of Calgary, Calgary, Alberta, Canada. ${ }^{6}$ Department of Psychiatry, University of Calgary, Calgary, Alberta, Canada.

Received: 10 March 2020 Accepted: 20 July 2020

Published online: 31 July 2020

\section{References}

1. Cavallazzi R, Saad M, Marik P. Delirium in the ICU: an overview. Ann Intensive Care. 2012;2(1):1-11

2. Collier R. Hospital-induced delirium hits hard. CMAJ. 2012;184(1):23-4.

3. Girard T, Jackson J, Pandaripande P, Pun B, Thompson J, Shintani A, et al. Delirium as a predictor of long-term cognitive impairment in survivors of critical illness. Crit Care Med. 2010;38(7):1513-20.

4. van den Boogaard M, Kox M, Quinn K, van Achterberg T, van der Hoeven J, Schoonhoven $\mathrm{L}$, et al. Biomarkers associated with delirium in critically ill patients and their relation with long-term subjective cognitive dysfunction; indications for different pathways governing delirium in inflamed and noninflamed patients. Crit Care. 2011;15(R297):1-9.

5. Van Rompaey B, Schuurmans MJ, Shortridge-Baggett LM, Truijen S, Elseviers M, Bossaert L. Long term outcome after delirium in the intensive care unit. J Clin Nurs. 2009;18(23):3349-57.

6. Shintani A, Girard T, Arbogast PG, Moons K, Ely E. Immortal time bias in critical care research: application of time-varying Cox regression for observational cohort studies. Crit Care Med. 2009:37(11):2939-45.

7. Ely EW, Shintani A, Truman B, Speroff T, Gordon SM, Harrell FE Jr, et al. Delirium as a predictor of mortality in mechanically ventilated patients in the intensive care unit. JAMA. 2004;291(14):1753-62.

8. Saczynski JS, Marcantonio ER, Quach L, Tamara GF, Gross A, Inouye SK, et al. Cognitive trajectories after postoperative delirium. N Engl J Med. 2012; 367(1):30-9.

9. Pandharipande PP, Girard TD, Jackson JC, Morandi A, Thompson JL, Pun BT, et al. Long-term cognitive impairment after critical illness. N Engl J Med. 2013;369(14):1306-16.

10. Wolters $A E$, Peelen $L M$, Welling MC, Kok L, de Lange DW, Cremer OL, et al. Long-term mental health problems after delirium in the ICU. Crit Care Med. 2016;44(10):1808-13.

11. Witlox J, Eurelings L, de Jonghe J, Kalisvaart K, Eikelenboom P, van Gool W Delirium in elderly patients and the risk of postdischarge mortality, institutionalization, and demenetia: a meta-analysis. JAMA. 2010; 304(4):443-51.
12. O'Sullivan R, Inouye SK, Meagher D. Delirium and depression: interrelationship and overlap in elderly people. Lancet Psychiatry. 2014;1(4):30311

13. Brummel N, Girard T. Preventing delirium in the intensive care unit. Crit Care Clin. 2013;29(1):51-65.

14. Sherin J, Nemeroff C. Post-traumatic stress disorder: the neurobiological impact of psychological trauma. Dialogues Clin Neurosci. 2011;13(3):263-78.

15. Granja C, Lopes A, Moreira S, Dias C, Costa-Pereira A, Carneiro A, et al. Patients' recollections of experiences in the intensive care unit may affect their quality of life. Crit Care. 2005;9(1):R96-R109.

16. Asimakopoulou E, Madianos M. The prevalence of major depression-PTSD comorbidity among ICU survivors in five general hospitals of Athens: a cross-sectional study. Issues Ment Health Nurs. 2014;35(12):954-63.

17. Davydow D, Gifford J, Desai S, Bienvenu O, Needham D. Depression in general intensive care unit survivors: a systematic review. Intensive Care Med. 2009;35(5):796-809

18. Davydow D, Hough C, Zatzick D, Katon W. Psychiatric symptoms and acute care service utilization over the course of the year following medicalsurgical ICU admission: a longitudinal investigation. Crit Care Med. 2014; 42(12):2473-81.

19. Apker J, Mallak LA, Gibson SC. Communicating in the "gray zone": perceptions about emergency physician-hospitalist handoffs and patient safety. Acad Emerg Med. 2007;14(10):884-94.

20. Griffiths J, Gager M, Waldmann C. Follow-up after intensive care. BJA Education. 2004:4(6):202-5.

21. Riesenberg LA, Leitzsch J, Massucci JL, Jaeger J, Rosenfeld JC. Residents' and attending physicians' handoffs: a systematic review of the literature. Acad Med. 2009;84(12):1775-87.

22. von Elm E, Altman DG, Egger M, Pocock S, Gøtzsche P, Vandenbroucke J, et al. The Strengthening the Reporting of Observational Studies in Epidemiology (STROBE) statement: guidelines for reporting observational studies. Ann Intern Med. 2007:147(8):573-7.

23. Statistics Canada. Alberta [Province] and Canada [Country] (table). Census Profile. 2016 Census statistics Canada catalogue no 98-316-X2016001. Ottawa 2017.

24. Chiasson TC, Manns BJ, Stelfox HT. An economic evaluation of venous thrombolism prophylaxis strategies in critically ill trauma patients at risk of bleeding. PLoS Med. 2009;6(6):e1000098.

25. Stelfox HT, Soo A, Niven DJ, Fiest KM, Wunsch H, Rowan KM, et al. Assessment of the safety of discharging select patients directly home from the intensive care unit: a multicenter population-based cohort study. JAMA Intern Med. 2018;178(10):1390-9.

26. Brundin-Mather R, Soo A, Zuege DJ, Niven DJ, Fiest KM, Doig CJ, et al. Secondary EMR data for quality improvement and research: a comparison of manual and electronic data collection from an integrated critical care electronic medical record system. J Crit Care. 2018;47:295-301.

27. Girard T, Pandaripande P, Ely EW. Delirium in the intensive care unit. Crit Care. 2008;12(Suppl 3):S3.

28. Fiest KM, Krewulak KD, Ely EW, Davidson JE, Ismail Z, Sept BG, et al. Partnering with family members to detect delirium in critically ill patients. Crit Care Med. 2020:48(7):954-61.

29. Bergeron N, Dubois M, Dumont M, Dial S, Skrobik Y. Intensive care delirium screening checklist: evaluation of a new screening tool. Intensive Care Med. 2001;27(1):859-64

30. Abraham CM, Obremskey WT, Song Y, Jackson JC, Ely EW, Archer KR. Hospital delirium and psychological distress at 1 year and health-related quality of life after moderate-to-severe traumatic injury without intracranial hemorrhage. Arch Phys Med Rehabil. 2014;95(12):2382-9.

31. Chlan L, Savik K. Patterns of anxiety in critically ill patients receiving mechanical ventilatory support. Nurs Res. 2011;60(3):S50-S7.

32. Guerra $C$, Linde-Zwirble WT, Wunsch H. Risk factors for dementia after critical illness in elderly Medicare beneficiaries. Crit Care. 2012;16(6):R233.

33. Jackson JC, Pandaripande P, Giard T, Brummel N, THompson J, Hughes C, et al. Depression, post-traumatic stress disorder, and functional disability in survivors of critical illness in the BRAIN-ICU study: a longitudinal cohort study. Lancet Respir Med. 2014;2(5):369-79.

34. American Psychiatric Association. Diagnostic and statistical manual of mental disorders: DSM-5. Washington, D.C: American Psychiatric Association; 2013.

35. Fiest KM, Jette N, Quan H, Germaine-Smith CS, Metcalfe A, Patten SB, et al. Systematic review and assessment of validated case definitions for depression in administrative data. BMC Psychiatry. 2014;14(289):1-11. 
36. Marrie RA, Walker JR, Graff LA, Lix LM, Bolton JM, Nugent Z, et al. Performance of administrative case definitions for depression and anxiety in inflammatory bowel disease. J Psychosom Res. 2016;89(1):107-13.

37. Kim H, Chung S, Joo YH, Lee JS. The major risk factors for delirium in a clinical setting. Neuropsychiatr Dis Treat. 2016;12(1):1787-93.

38. Rawal G, Yadav S, Kumar R. Post-intensive care syndrome: an overview. J Transl Int Med. 2017;5(2):90-2.

39. Fong TG, Tulebaez SR, Inouye SK. Delirium in elderly adults: diagnosis, prevention and treatment. Nat Rev Neurol. 2009;5(4):210-20.

40. Momennasab M, Ghahramani T, Yektatalab S, Zand F. Physical and mental health of patients immediately after discharge from intensive care unit and 24 hours later. Trauma Mon. 2016;21(1):e29231.

41. Paparrigopoulos T, Melissaki A, Tzavellas E, Karaiskos D, llias I, Kokras N. Increased co-morbidity of depression and post-traumatic stress disorder symptoms and common risk factors in intensive care unit survivors: a twoyear follow-up study. Int J Psychiatry Clin Pract. 2014;18(1):25-31.

42. Patten SB, Williams JV, Lavorato DH, Fiest KM, Bulloch AG, Wang J. The prevalence of major depression is not changing. Can J Psychiatr. 2015;60(1): 31-4.

43. Robins LN, Helzer JE, Weissman MM, Orvaschel H, Gruenberg E, Burke JDJ, et al. Lifetime prevalence of specific psychiatric disorders in three sites. Arch Gen Psychiatry. 1984:41(1):949-58.

44. Kessler RC, Petukhova M, Sampson NC, Zalslavsky AM, Wittchen H-U. Twelve-month and lifetime prevalence and lifetime morbid risk of anxiety and mood disorders in the United States. Int J Methods Psychiatr Res. 2012; 21(3):169-84.

45. Chahraoui K, Laurent A, Bioy A, Quenot J-P. Psychological experience of patients 3 months after a stay in the intensive care unit: a descriptive and qualitative study. J Crit Care. 2015;30(3):599-605.

46. Rattray JE, Johnston M, Wildsmith JAW. Predictors of emotional outcomes of intensive care. Anaesthesia. 2005;60(11):1085-92.

47. Battle $C$, James $K$, Temblett $P$. Depression following critical illness: analysis of incidence and risk factors. J Intensive Care Soc. 2015;16(2):105-8.

48. Ballenger JC. Anxiety and depression: optimizing treatments. Prim Care Companion J Clin Psychiatry. 2000:2(3):71-9.

49. Modrykamien AM. The ICU follow-up clinic: a new paradigm for intensivists. Respir Care. 2012;57(5):764-72.

50. Prinijha S, Field K, Rowan K. What patients think about ICU follow-up services: a qualitative study. Crit Care. 2009;13(R46):1-10.

51. Garand L, Lingler JH, Conner KO, Dew MA. Diagnostic labels, stigma, and participation in research related to dementia and mild cognitive impairment. Res Gerontol Nurs. 2009;2(2):112-21.

52. Gulliver A, Griffiths $\mathrm{K}$, Christensen $\mathrm{H}$. Perceived barriers and facilitators to mental health help-seeking in young people: a systematic review. BMC Psychiatry. 2010;10(113):1-9.

\section{Publisher's Note}

Springer Nature remains neutral with regard to jurisdictional claims in published maps and institutional affiliations.

Ready to submit your research? Choose BMC and benefit from:

- fast, convenient online submission

- thorough peer review by experienced researchers in your field

- rapid publication on acceptance

- support for research data, including large and complex data types

- gold Open Access which fosters wider collaboration and increased citations

- maximum visibility for your research: over $100 \mathrm{M}$ website views per year

At $\mathrm{BMC}$, research is always in progress.

Learn more biomedcentral.com/submissions 